\title{
İntrasitoplazmik sperm enjeksiyonu (ICSI) uygulanan infertil kadınlarda gebelik başarısını etkileyen faktörlerin değerlendirilmesi
}

\author{
Evaluation of factors influencing pregnancy success rate in infertile women who \\ underwent intracytoplasmic sperm injection (ICSI)
}

\author{
Ümit Çabuş, Nazıı Çil, Cihan Kabukçu
}

\section{Öz}

Amaç: Çalışmamızın amacı, yardımcı üreme tekniği olarak intrasitoplazmik sperm enjeksiyonu uygulanan infertil kadınlarda gebelik başarısını etkileyen faktörlerin değerlendirilmesidir.

Gereç ve yöntem: Ocak 2018 ve Aralık 2020 tarihleri arasında, intrasitoplazmik sperm enjeksiyonu uygulanan, tek ve taze embriyo transferinin yapıldığı toplam 283 infertil hastaya ait 325 siklus çalışmaya dâhil edildi. Hastaların yaşı, vücut kitle indeksleri, infertilite nedenleri, kaç adet oosit toplandığı ve maturasyon oranı, embriyo transfer günü endometriyal kalınlık, embriyonun kalitesi ve kaçıncı gün transfer edildiği belirlendi. Ayrıca hastaların Anti-Müllerian Hormon (AMH), bazal FSH, LH, estradiol (E2) düzeyleri, Human Chorionic Gonadotropin (hCG) uygulandığı gün E2 ile progesteron $(P)$ düzeyleri ve gebelik sonuçları değerlendirildi.

Bulgular: Gebelik oluşan sikluslarda ( $\mathrm{n}: 141)$, oluşmayan sikluslara ( $\mathrm{n}: 184)$ kıyasla kadın yaşı ( $31,57 \pm 4,33$ vs. $32,95 \pm 5,55, p=0,015)$, bazal FSH seviyesi $(7,51 \pm 4,30$ vs. $8,23 \pm 3,64, p=0,005)$, AMH $(2,99 \pm 2,39$ vs. $2,70 \pm 3,19$, $p=0,002)$, elde edilen oosit sayısı $(11,54 \pm 6,87$ vs. $9,81 \pm 7,61, p=0,003)$, MII oosit sayıs $(9,55 \pm 6,2$ vs. $7,57 \pm 5,91$, $p=0,001)$, embriyo kalitesi $\left(X^{2}=13,46, p<0,001\right)$ ve 5 . gün embriyo transfer oranı $\left(X^{2}=15,40, p<0,0001\right)$ istatiksel olarak anlamlı bulundu. VKí, bazal E2 seviyesi, hCG günü E2 ve $p$ seviyesi, ET günü EMK, oosit maturasyon indeksi ve total pogressif motil sperm sayısı açısından her iki grup arasında anlamlı bir farklılık gözlenmedi $(p>0,05)$. Infertilite nedenlerinin gebelik oluşumuna etkisi değerlendirildiğinde gruplar arasında anlamlı fark olmadığı izlendi.

Sonuç: ICSI uygulanan infertil kadınlarda gebelik başarısını öngörmede en önemli prognostik faktörler maternal yaş, embriyo kalitesi ve transfer günüdür.

Anahtar kelimeler: Infertilite, intrasitoplazmik sperm enjeksiyonu, embriyo kalitesi, gebelik.

Çabuş Ü, Çil N, Kabukçu C. İntrasitoplazmik sperm enjeksiyonu (ICSI) uygulanan infertil kadınlarda gebelik başarısını etkileyen faktörlerin değerlendirilmesi. Pam Tıp Derg 2021;14:748-759.

\footnotetext{
Abstract

Purpose: The aim of our study is to evaluate the factors affecting pregnancy success rate in infertile women who underwent intracytoplasmic sperm injection as an assisted reproductive technique.

Materials and methods: Between January 2018 and December 2020, 325 cycles of 283 infertile patients who underwent intracytoplasmic sperm injection and a single fresh embryo transfer were included in the study. Age of patients, BMI, causes of infertility, number of collected oocytes and maturation rate, endometrial thickness on embryo transfer day, quality of embryo and transfer day were determined. In addition, anti-Müllerian Hormone, basal FSH, LH, estradiol (E2) levels and E2 and progesterone (P) levels on the day of Human Chorionic Gonadotropin ( $\mathrm{hCG}$ ) administration and pregnancy outcomes were evaluated.

Results: Age of women ( $31.57 \pm 4.33$ vs. $32.95 \pm 5.55, p=0.015)$, basal FSH level $(7.51 \pm 4.30$ vs. $8.23 \pm 3.64$, $p=0.005)$, AMH (2.99 \pm 2.39 vs. $2.70 \pm 3.19, p=0.002)$, number of oocytes obtained $(11.54 \pm 6.87$ vs. $9.81 \pm 7.61$, $p=0.003)$, number of MII oocytes $(9.55 \pm 6.2$ vs. $7.57 \pm 5.91, p=0.001)$, embryo quality $\left(x^{2}=13.46, p<0.001\right)$ and embryo transfer rate on fifth day $\left(X^{2}=15.40, p<0.0001\right)$ were found to be statistically significant in cycles resulting in a pregnancy (n:141) compared to nonsuccesful cycles (n:184). BMI, basal E2 level, E2 and p levels on hCG day, EMT on ET day, oocyte maturation index and total progressive motile sperm count were not significantly different between the groups $(p>0.05)$. When the effects of infertility causes on pregnancy succes rate were evaluated, there was no significant differences between the groups.

Conclusion: The most important prognostic factors in predicting pregnancy success rate in infertile women who underwent ICSI are maternal age, embryo quality and transfer day.
}

Ümit Çabuş, Dr. Öğr. Üye. Pamukkale Üniversitesi Tıp Fakültesi, Kadın Hastalıkları ve Doğum Anabilim Dalı, Denizli, Türkiye, e-posta: umitcabus@gmail.com (https://orcid.org/0000-0001-5478-5673) (Sorumlu Yazar)

Nazlı Çil, Dr Öğr. Üye. Pamukkale Üniversitesi Tıp Fakültesi, Histoloji ve Embriyoloji AD, Denizli, Türkiye, e-posta: ncil@pau.edu.tr (https://orcid. org/0000-0002-2164-8688)

Cihan Kabukçu, Dr. Öğr. Üye. Pamukkale Üniversitesi Tıp Fakültesi, Kadın Hastalıkları ve Doğum Anabilim Dalı, Denizli, Türkiye, e-posta: cihankabukcu@yahoo.com (https://orcid.org/0000-0003-3331-5714) 
Key words: Infertility, intracytoplasmic sperm injection, embryo quality, pregnancy.

Cabus U, Cil N, Kabukcu C. Evaluation of factors influencing pregnancy success rate in infertile women who underwent intracytoplasmic sperm injection (ICSI). Pam Med J 2021;14:748-759.

\section{Giriş}

Illk kez 1978 yılında Roberts Edwards ve Patrick Steptoe tarafından uygulanan in vitro fertilizasyon (IVF) yöntemi ile elde edilen gebeliğin canlı doğum ile sonuçlanması, infertilite tedavisinde bir çığır açmıştır [1]. Bu tarihten itibaren yardımcı üreme teknikleri (YÜT) hızla gelişmiş ve bu yöntemler kullanılarak dünya genelinde 8 milyondan fazla bebek doğmuştur [2]. Günümüzde ise $A B D$ ve Avrupa'daki doğumların \%1-4,5'i YÜT ile oluşan gebeliklerden oluşmaktadır $[3,4]$.

Yıllar içinde YÜT olarak tubaya oosit ve sperm transferi (GIFT), zigot transferi (ZIFT) ve embriyo transferi (TET) gibi teknikler denenmiş olsa da günümüzde en sık IVF ve intrasitoplazmik sperm enjeksiyonu (ICSI) yöntemleri kullanılmaktadır [5]. Bu iki yöntem gonadotropinlerle overyan stimülasyon uygulanması, overyan yanıt ve endometriyal kalınlığın takibi sonrası ovulasyonun tetiklenmesi, transvajinal ultrasonografi eşliğinde oositlerin toplanması, laboratuvar ortamında fertilizasyon ve embriyo kültür işleminin yapılması ve hazırlanan embriyonun transservikal yolla endometriyuma transfer edilmesi gibi bir dizi basamaklar içerir.

Nihai hedefi gebelik elde edilmesi olan bu süreçteki asıl belirleyici nokta ise embriyonun implantasyon aşamasıdır. Embriyo implantasyonu, hem embriyo hem de maternal endometriyumu ilgilendiren karmaşık bir süreçtir ve başlangıç adımları midluteal faz sırasında yaklaşık 4-6 günlük bir aralıkta gerçekleşir. Bu aralık blastokist trofektoderminin endometriyal epitel hücrelerine bağlanabileceği ve sonrasında endometriyal stroma ve vasküler alanları istila etmeye devam edebileceği, endometriyal reseptivitenin en yüksek olduğu olgunlaşma dönemidir [6].

YÜTkullanılarakuygulanantedavilerlegebelik elde edilmesi ve bu gebeliğin canlı doğumla sonuçlanması birçok değişkene bağlıdır. Bu çalışmanın amacı, tüp bebek ünitemizde, ICSI yöntemi uygulanan infertil hastalarda klinik gebelik başarısına etkisi olabileceği düşünülen yaş, vücut kitle indeksi (VKI), infertilite nedeni, toplanan oosit sayısı ve maturasyon oranı, transfer edilen embriyonun kalitesi, transfer günü endometriyum kalınlığı, antimüllerian hormon $(\mathrm{AMH})$ ve diğer hormon değerleri gibi parametrelerin değerlendirilmesidir.

\section{Gereç ve yöntem}

Ocak 2018 ve Aralık 2020 tarihleri arasında Pamukkale Üniversitesi Tıp Fakültesi Yardımcı Üreme Teknikleri Merkezinde, kontrollü overyan stimülasyonu takiben ICSI (Resim 1) uygulanan toplam 283 infertil hastaya ait 325 siklus çalışmaya dâhil edildi. Pamukkale Üniversitesi Girişimsel Olmayan Klinik Araştırmalar Etik Kurulu'ndan etik onayı alındı. Ayrıca tüm prosedürler Helsinki Bildirgesi'nin ilkelerine uygun olacak şekilde uygulandı. Hasta bilgileri, hasta dosyalarından ve hastane kayıt sisteminden elde edildi.

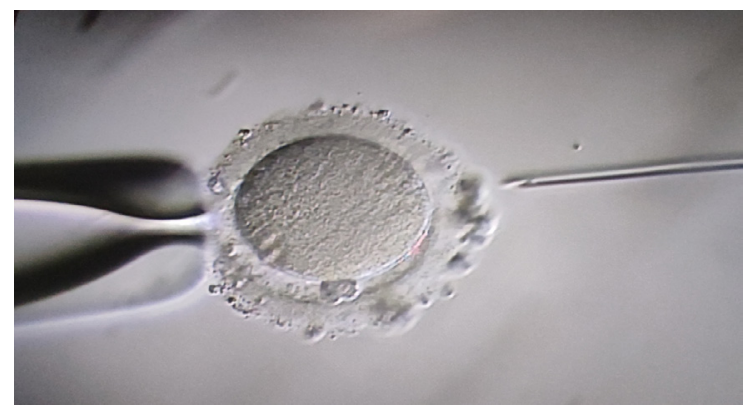

Resim 1. İntrasitoplazmik sperm enjeksiyonu (ICSI). Inverted mikroskop, 20X, Pamukkale Üniversitesi Yardımcı Üreme Teknikleri Merkezi Arşivi

Hastaların yaşı, vücut kitle indeksleri (VKI), infertilite nedenleri, toplam oosit, oositlerin maturasyon oranı, transfer edilen embriyonun kalitesi ve transfer günü endometriyal kalınlık (EMK) belirlendi. Ayrıca hastaların Anti-Müllerian Hormon (AMH), bazal folikül uyarıcı hormon $(\mathrm{FSH})$, luteinize edici hormon (LH), estradiol (E2) düzeyleri, Human Chorionic Gonadotropin (hCG) uygulandığı gün estradiol ile progesteron $(P)$ düzeyleri ve gebelik sonuçları değerlendirildi.

Oosit toplama işleminde elde edilen oosit sayılarına göre 1-5 arası oosit grup I, 6-10 
arası oosit grup II, 11-15 arası oosit grup III ve $\geq 16$ oosit ise grup IV olarak gruplandırıldı. ICSI tedavi sikluslarının sonucuna göre hastalar gebelik var ve gebelik yok olarak iki gruba ayrıldı. Transvajinal ultrasonografide bir veya daha fazla gebelik kesesinin varlığı klinik gebelik olarak tanımlandı. Klinik gebelikte kendi içinde üçe ayrıldı. 20. gebelik haftasından önce gebelik kayıpları "abort grubu", gebelik haftası 20 haftayı aşan ve henüz doğum yapmamış olanlar "devam eden gebelik grubu" ve doğumu gerçekleşmiş hastalar ise "doğum grubu" olarak gruplandırıldı. Gebelik testi pozitif olan ancak biyokimyasal gebelik veya ektopik gebelik ile sonuçlanan sikluslar çalışmaya dâhil edilmedi.

\section{Hastaların infertilite nedenlerine gruplandırılmaları}

İnertilite nedenleri zayıf over yanıtı (ZOY), erkek faktör (EF), tubal faktör (TF), açıklanamayan infertilite (AI), anovulatuar siklus (AOS) ve ZOY+EF olarak gruplandırıldı.

Zayıf over yanıtının tanısında 2010 yılı ESHRE konsensüsünde belirlenen Bologna Kriterleri [İleri anne yaşı ( $\geq 40)$ veya düşük over rezervi (DOR) için herhangi bir risk faktörü olması, geçmişte DOR öyküsü (klasik bir stimülasyon protokolü ile $\leq 3$ oosit elde edilmesi) ve anormal over rezervi testi bulunması (toplamda antral follikül sayısının $<5-7$ veya AMH değerinin $<0,5-1,1 \mathrm{ng} / \mathrm{ml}$ olması] esas alındı. Bu konsensüste belirlenen üç kriterden ikisinin varlığı ile hastalara zayıf over yanıtı tanısı konuldu [7]. Çalışmamızda, toplam antral folikül sayısı ve AMH değeri için cut off değerleri sırasıyla $\leq 6$ ve $<1,0 \mathrm{ng} / \mathrm{ml}$ olarak belirlenmiştir.

Erkek faktör tanısı, 15 gün arayla ve 3 ile 5 günlük cinsel perhiz sonrası verilen 2 farklı spermiogram örneğinin, Dünya Sağlık Örgütü (WHO) 2010 semen özellikleri için referans sınırlarına (volume $\geq 1,5 \mathrm{~mL}$, konsantrasyon $\geq 15$ milyon $/ \mathrm{mL}$, total sperm sayısı $\geq 39$ milyon, progresif hareketli sperm sayısı $\geq \% 32$, canlılık $\geq \% 58$, ve Kruger'e göre normal morfoloji >\%4) göre konuldu [8]. ICSI öncesi spermler dansite gradient yöntemiyle hazırlandı.

Tubal faktör tanısı, tedavi öncesi histerosalfingografi veya aynı seansta yapılan histeroskopi + laparoskopi ile bilateral tuba anatomisinin bozulduğu ve tubal pasajın olmadığının görülmesi ile konuldu.
Açıklanmayan infertilite tanısı diğer infertilite nedenlerinin dışlanması ile konuldu. Keskin sınırları olmasa da literatürdeki en yaygın açıklanamayan infertilite tanımı olan "normal bir ovulasyon fonksiyonu, normal sperm parametreleri ve en az bir tane işlevsel tuba uterina olmasına rağmen infertilitenin varlığı" esas alındı. [9].

Anovulatuar siklus tanısı, ultrasonografik bulgularla ovulasyonun olmadığının tespit edilmesi ve menstrüel döngünün midluteal fazında alınan progesteron değerlerinin $<3 \mathrm{ng} /$ ml'den az olması ile konuldu.

\section{Embriyo kalitesinin derecelendirilmesi}

ICSI işlemi sonrası gelişen embriyoların transferi, bu embriyoların sayı ve kalitesine bağlı olarak 3 . veya 5 . günde yapılmaktadır. Transfer edilecek embriyo kalitelerinin değerlendirilmesinde Gardner ve Schoolcraft sınıflaması kullanıldı [10]. 3. gün embriyoları blastomer sayısı, blastomerlerin simetrisi ve fragmantasyon oranlarına göre derecelendirildiğinde birinci kalite embriyolar; Grade 1, ikinci kalite embriyolar; Grade 2, üçüncü kalite embriyolar; Grade 3 olarak sınıflandırıldı. Beşinci gün embriyoları ise blastosel büyüklüğü, iç hücre kitlesi ve trofoektoderm yapılarına göre derecelendirilerek 4AA, 4AB, 5AA birinci kalite embriyolar, 3AA, 3BB, 3BC ikinci kalite embriyolar ve erken blast (EB) üçüncü kalite embriyolar olarak kabul edildi (Resim 2 ve 3). Transfer edilen tüm embriyolar taze embriyolardı.

\section{Embriyo transfer tekniği}

Serum fizyolojik ve besi yeri ile vajen temizliği yapıldı. Servikal kanal mukusu kanül ile aspire edilerek temizlendi. Seçilen embriyo ya da embriyolar önceki gün hazırlanmış ve gazlanmış bikarbonat tamponlu mediumun içine konularak, yine aynı medium ile yıkanmış Hamilton enjektör yardımıyla yumuşak transfer kataterine steril bir şekilde yerleştirildi. Transfer kateterine yüklenen embriyolar mesane dolu iken transabdominal ultrasonografi eşliğinde, uterin fundusa dokunulmadan, fundusa en az 1 cm uzaklıktaki uterusun üst veya orta kısmındaki alana bırakıldı. Embriyo transfer tekniği olarak 2017 yılında yayınlanan ASRM klavuzu esas alındı [11]. 


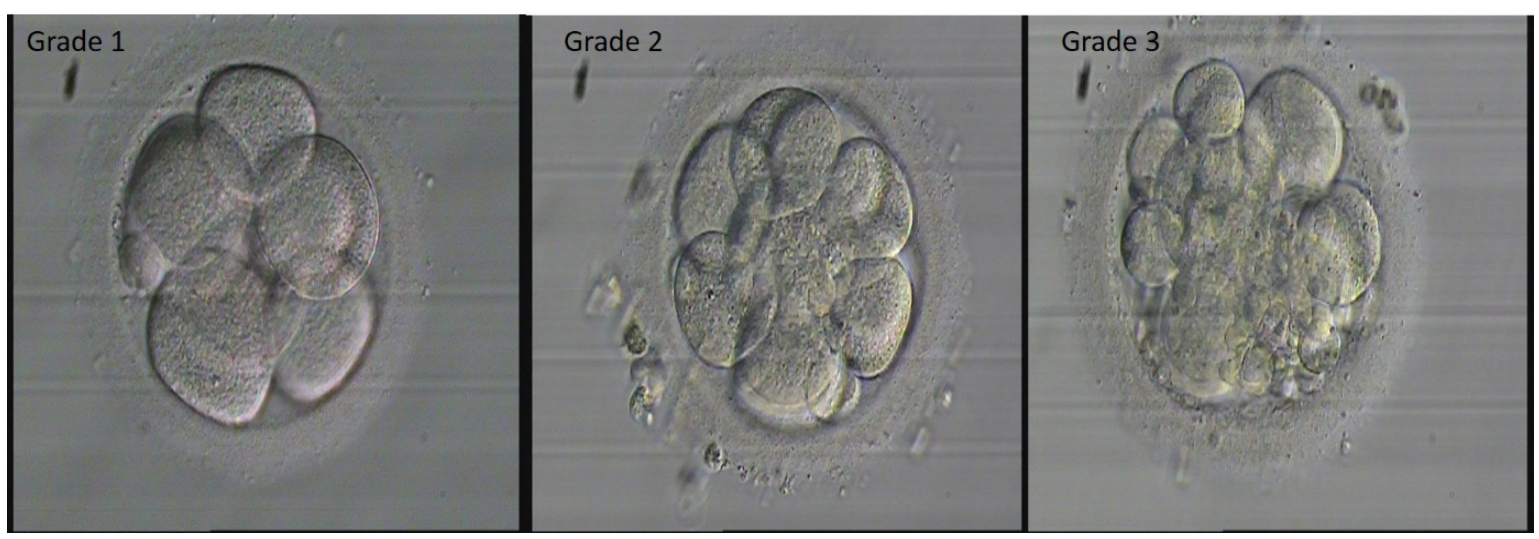

Resim 2. Üçüncü gün embriyoların derecelendirilmesi. Inverted mikroskop, 20X, Pamukkale Üniversitesi Yardımcı Üreme Teknikleri Merkezi Arşivi

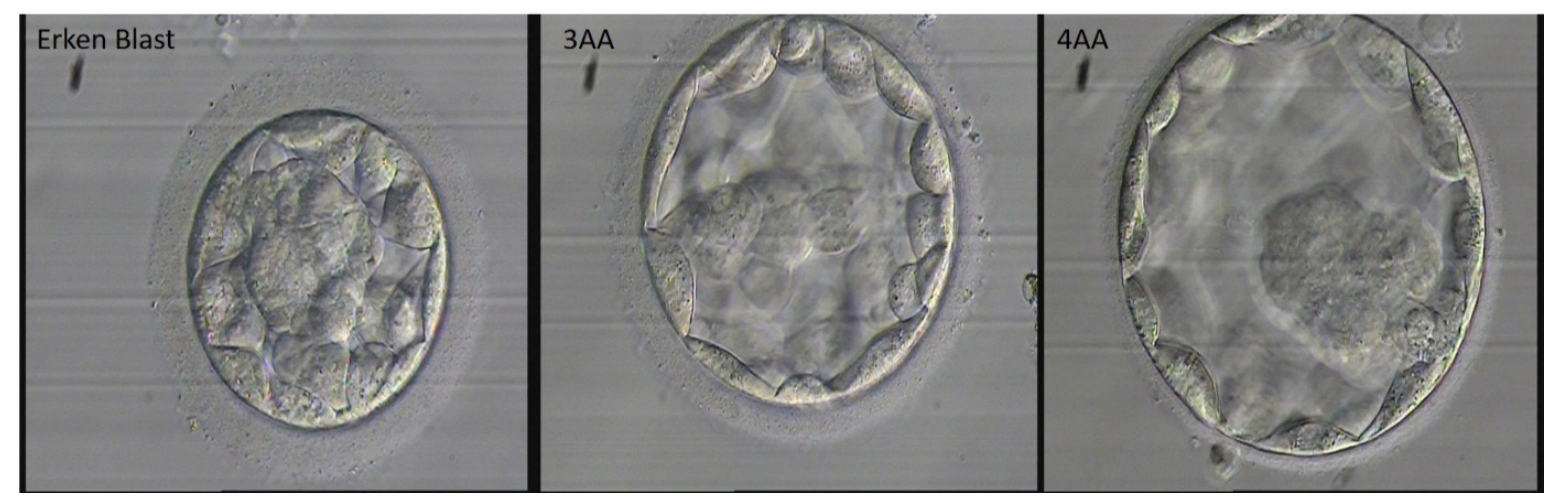

Resim 3. Beşinci gün embriyoların derecelendirilmesi. Inverted mikroskop, 20X, Pamukkale Üniversitesi Yardımcı Üreme Teknikleri Merkezi Arşivi

\section{Endometriyal kalınlık değerlendirmesi}

Endometrium görüntülemesi, embriyo transfer günü transvajinal ultrasonografiyle 2 boyutlu olarak, endometriyal kavitenin bütün aksı görünecek şekilde yapıldı. Endometriyal kalınlık ölçümü sagittal planda, kavitenin ön ve arka duvarları arası mesafenin kaviteye dik olacak şekilde 2 kez ölçülmesiyle yapıldı. Ölçümlerin ortalaması kayıt altına alındı. Bütün endometriyal kalınlık ölçümleri aynı cihaz ve aynı hekim tarafından yapıldı.

\section{Hasta dışlama kriterleri}

Dondurulmuş veya birden fazla sayıda taze embriyo transferi yapılan tedavi siklusları çalışma dışı bırakıldı. Servikal kanalı stenotik olan ve zor transfer olarak kabul edilen uygulamalar çalışmaya dâhil edilmedi.

Ultrasonografi (USG), salin infüzyon sonografi (SiS), histerosalfingografi (HSG) veya histeroskopi $(H / S)$ yöntemleriyle tespit edilen endometrial polip, uterin anomali, uterin fibroid ve adenomyozis gibi anormal uterin kaviteye neden olan patolojiye sahip hastalar çalışma dışı bırakıldı.

Ayrıca uterus enstrümantasyonu (dilatasyon ve küretaj (D\&C), histeroskopik cerrahi, vb) veya uterin cerrahi (örneğin endometrial kaviteyle ilişkili myomektomi) öyküsü olan hastalar da çalışma dışı bırakıldı. Böylece yetersiz uterin kavitenin olduğu, endometriyal kavitenin bütünlüğünün bozulduğu, endometriumun hasarlandığı, reseptivite ve/veya implantasyonu olumsuz etkileyebilecek nedenler dışlandı.

\section{İstatiksel analiz}

Araştırma sonuçlarından elde edilen veriler SPSS 21 (Statistical Package for the Social Sciences versiyon 21, Chicago, IL, USA) paket programı ile değerlendirilmiştir. Analizlerde verilerin tanımlayıcı özellikleri; kategorik veriler için sayı (n) ve yüzde (\%), sayısal değişkenler için ortalama \pm standart sapma, ortanca (minimum ve maksimum değerler) değeri olarak 
sunuldu. Verilerin normal dağılıma uygunluğu histogram ve Kolmogorov-Smirnoff Testi ile incelendi. Normal dağılım özelliği göstermeyen iki bağımsız grubun karşılaştııılmasında nonparametrik yöntem olarak Mann Whitney U testi kullanıldı. İki bağımsız örneklemden elde edilen ortalamalar arasındaki farkın anlamlılığını test etmek için parametrik bir test olan Bağımsız Örneklem T testi kullanıldı. Kategorik değişkenler ki-kare testi ile değerlendirildi. Sürekli değişkenler arasındaki ilişkiler Spearman korelasyon analizi ile incelendi. Gebeliğe etki eden faktörler çoklu lojistik regresyon analizi ile değerlendirildi. $P<0,05$ istatistiksel olarak anlamlı kabul edildi.

\section{Bulgular}

Çalışmaya tek embriyo transferinin yapıldığı, 283 infertil hastaya ait 325 siklus dâhil edildi. Hastaların yaş ortalaması $32,33 \pm 5,23$ yıl olarak bulundu. İnfertilite nedeni olarak 92 $(\% 32,5)$ hastada açıklanamayan infertilite, 41 $(\% 14,5)$ hastada anovulatuar siklus, $70(\% 24,7)$ hastada erkek faktör, $61(\% 21,6)$ hastada zayıf over yanıtı, $11(\% 3,9)$ hastada tubal faktör ve 8 hastada $(\% 2,8) E F+Z O Y$ tanıları mevcuttu. Hastaların ortalama VKI $24,96 \pm 4,88$ bulunurken, diğer demografik özellikler Tablo 1 'de gösterilmiştir.

Uygulanan toplam 325 ICSI siklusundan 141 siklus sonucunda klinik gebelik $(\% 43,4)$ elde edilirken, 184 siklus sonucunda ise gebelik elde edilememiştir $(\% 56,6)$. Ultrasonografik değerlendirme sonucuna göre oluşan gebeliklerden $18 \quad(\% 12,76)$ tanesi çoğul gebelikti. Geri kalan $123(\% 87,23)$ gebelikte ise tek fetüs izlendi. Elde edilen gebeliklerden $35^{\prime}$ i $(\% 24,82)$ gebeliğin ilk 20 haftası içinde abortus ile sonuçlanırken, $80(\% 56,8)$ tanesi canlı doğum ile sonuçlanmıştır. $26(\% 18,44)$ gebelik ise hâlen intrauterin devam etmektedir.

Tablo 2'de gebeliğe etkisi olduğu düşünülen prognostik faktörler değerlendirilmiştir. Buna göre gebelik oluşan sikluslarda (n:141), oluşmayan sikluslara (n:184) kıyasla kadın yaşı $(31,57 \pm 4,33$ vs. $32,95 \pm 5,55, p=0,015)$, bazal FSH seviyesi $(7,51 \pm 4,30$ vs. $8,23 \pm 3,64$,

Tablo 1. Hastaların demografik verileri ve özellikleri

\begin{tabular}{|c|c|c|}
\hline Hasta sayısı & \multicolumn{2}{|l|}{283} \\
\hline Siklus sayısı & \multicolumn{2}{|l|}{325} \\
\hline Yaş (yıl) (mean \pm SD) & \multicolumn{2}{|c|}{$32,33 \pm 5,23$} \\
\hline $\begin{array}{l}\text { Grup I ( } 20-29 \text { yaş) } \\
\text { Grup II (30-39 yaş) } \\
\text { Grup III ( } \geq 40 \text { yaş) }\end{array}$ & \multicolumn{2}{|c|}{$\begin{array}{l}105(\% 32,3) \\
198(\% 60,9) \\
22(\% 6,8)\end{array}$} \\
\hline VKI (kg/m2) & \multicolumn{2}{|c|}{$24,96(16,16-41,02)^{a}$} \\
\hline İnfertilite nedeni & $\mathbf{n}$ & (\%) \\
\hline Açıklanamayan & 92 & $(32,5)$ \\
\hline Anovulatuvar & 41 & $(14,5)$ \\
\hline Erkek faktör & 70 & $(24,7)$ \\
\hline Zayıf Over Yanıtı & 61 & $(21,6)$ \\
\hline Tubal Faktör & 11 & $(3,9)$ \\
\hline \multirow[t]{2}{*}{ ZOY+EF } & 8 & $(2,8)$ \\
\hline & \multicolumn{2}{|l|}{283} \\
\hline \multicolumn{3}{|c|}{ Overyan rezerv değerleri } \\
\hline $\mathrm{AMH}(\mu \mathrm{g} / \mathrm{L})$ & \multicolumn{2}{|c|}{$1,98(0,01-16,17)^{a}$} \\
\hline Bazal FSH (IU/L) & \multicolumn{2}{|c|}{$7,08(1,56-33,97)^{a}$} \\
\hline Bazal LH (IU/L) & \multicolumn{2}{|c|}{$5,98(0,83-31,65)^{a}$} \\
\hline Bazal E2 (IU/L) & \multicolumn{2}{|c|}{$39,6(5,00-325,0)^{a}$} \\
\hline TPMSS & \multicolumn{2}{|c|}{$36(3-103,05)^{a}$} \\
\hline
\end{tabular}

VKI: vücut kitle indeksi, AMH: antimüllerian hormon, $\mathrm{FSH}$ : folikül stimülan hormon

LH: lütenizan hormon, E2: estradiol, P: progesteron

TPMSS: total progressif motil sperm sayısı

a (ortanca / min.-maks.) 
Tablo 2. Prognostik faktörlerin gebelik başarısına göre analizi

\begin{tabular}{|c|c|c|c|}
\hline & Gebelik VAR $(n=141)$ & Gebelik YOK $(n=184)$ & \\
\hline & $\begin{array}{l}\text { Ortalama } \pm \text { SS } \\
\text { Ortanca (min.-maks.) }\end{array}$ & $\begin{array}{l}\text { Ortalama } \pm \text { SS } \\
\text { Ortanca (min.-maks.) }\end{array}$ & $p$ \\
\hline \multirow[t]{2}{*}{ Hasta yaşı (yıl) } & $31,57 \pm 4,33$ & $32,95 \pm 5,55$ & \multirow{2}{*}{$0,015^{\star}$} \\
\hline & $31,0(20,0-45,0)$ & $33,0(20,0-49,0)$ & \\
\hline \multirow[t]{2}{*}{ VKI $\left(\mathrm{kg} / \mathrm{m}^{2}\right)$} & $26,06 \pm 5,40$ & $25,60 \pm 4,46$ & \multirow{2}{*}{$0,814^{\star *}$} \\
\hline & $25,20(16,16-41,02)$ & $25,12(16,94-40,23)$ & \\
\hline \multirow[t]{2}{*}{ Basal FSH (IU/L) } & $7,51 \pm 4,30$ & $8,23 \pm 3,64$ & \multirow{2}{*}{$0,005^{\star *}$} \\
\hline & $6,68(1,56-40,69)$ & $7,61(2,82-33,04)$ & \\
\hline \multirow[t]{2}{*}{ Basal E2 (ng/L) } & $44,01 \pm 24,23$ & $46,81 \pm 31,89$ & \multirow{2}{*}{$0,411^{\text {** }}$} \\
\hline & $40,20(6,42-189,00)$ & $41,37(5,50-325,00)$ & \\
\hline \multirow[t]{2}{*}{$\mathrm{AMH}(\mu \mathrm{g} / \mathrm{L})$} & $2,99 \pm 2,39$ & $2,70 \pm 3,19$ & \multirow{2}{*}{$0,002^{* *}$} \\
\hline & $2,40(0,01-13,85)$ & $1,44(0,05-16,17)$ & \\
\hline \multirow[t]{2}{*}{ hCG günü E2 (ng/L) } & $1713 \pm 889$ & $1529 \pm 892$ & \multirow{2}{*}{$0,056^{* *}$} \\
\hline & $1656(145-3000)$ & $1272(83-3000)$ & \\
\hline \multirow[t]{2}{*}{ hCG günü $P$ ( $\mu g / L)$} & $0,56 \pm 0,42$ & $0,67 \pm 0,62$ & \multirow{2}{*}{$0,119^{* *}$} \\
\hline & $0,46(0,07-3,06)$ & $0,50(0,05-5,9)$ & \\
\hline \multirow[t]{2}{*}{ ET günü EMK(mm) } & $11,46 \pm 2,59$ & $11,12 \pm 2,56$ & \multirow[t]{2}{*}{$0,146^{* *}$} \\
\hline & $11,46(6,00-20,00)$ & $10,80(6,00-19,40)$ & \\
\hline \multirow[t]{2}{*}{ Elde edilen oosit sayısı (n) } & $11,54 \pm 6,874$ & $9,81 \pm 7,610$ & \multirow{2}{*}{$0,003^{* *}$} \\
\hline & $10(2-36)$ & $8(1-45)$ & \\
\hline \multirow[t]{2}{*}{ Elde edilen metafaz II oosit sayısı ( $n$ ) } & $9,55+6,20$ & $7,57+5,91$ & \multirow[t]{2}{*}{$0,001^{* *}$} \\
\hline & $8(1-32)$ & $6(1-34)$ & \\
\hline \multirow[t]{2}{*}{ Maturasyon indeksi (\%) } & $82,46 \pm 18,16$ & $78,59 \pm 20,75$ & \multirow{2}{*}{$0,140^{* *}$} \\
\hline & $85,49(20,00-100,00)$ & $81,81(18,18-100,00)$ & \\
\hline \multicolumn{4}{|l|}{ Elde edilen oosit sayısı, n, (\%) } \\
\hline $0-5$ & $29(\% 20,6)$ & $59(\% 32,1)$ & \multirow{4}{*}{$\begin{array}{l}X^{2}=6,04 \\
0,110^{* * *}\end{array}$} \\
\hline $6-10$ & $46(\% 32,6)$ & $58(\% 31,5)$ & \\
\hline $11-15$ & $33(\% 23,4)$ & $34(\% 18,5)$ & \\
\hline$\geq 16$ & $33(\% 23,4)$ & $33(\% 17,9)$ & \\
\hline \multicolumn{4}{|l|}{ Embriyo transfer günü } \\
\hline 3. gün & $62(\% 44,0)$ & $121(\% 65,8)$ & \multirow{2}{*}{$\begin{array}{l}x^{2}=15,40 \\
<0,0001^{* * *}\end{array}$} \\
\hline 5. gün & $79(\% 56,0)$ & $63(\% 34,2)$ & \\
\hline \multicolumn{4}{|l|}{ Embriyo kalitesi } \\
\hline 1. kalite & $91(\% 64,5)$ & $82(\% 44,6)$ & \multirow{3}{*}{$\begin{array}{l}X^{2}=13,46 \\
0.001^{* * *}\end{array}$} \\
\hline 2. kalite & $33(\% 23,4)$ & $60(\% 32,6)$ & \\
\hline 3. kalite & $17(\% 12,1)$ & $42(\% 22,8)$ & \\
\hline TPMSS $\left(\times 10^{6}\right)$ & $29,10 \pm 22,36$ & $20,45 \pm 19,51$ & $0,747^{\star *}$ \\
\hline & $24,00(14,00-41,00)$ & $15,00(6,00-29,00)$ & \\
\hline
\end{tabular}

SS: standard sapma, VKI: vücut kitle indeksi, AMH: antimüllerian hormon, E2: estradiol, P: progestereon, hCG: human chorionic gonadotropin, ET: embriyo transferi, EMK: endometriyal kalınlık, TPMSC: total progressif motil sperm sayıSı,

* Bağımsız Örneklem T testi

** Mann Whitney U test

${ }^{* * *}$ Ki-kare test

$p$ değerinin 0,05 'ten küçük olması $(p<0,05)$ istatiksel olarak anlamlıdır. Kalın ve koyu yazılmış değerler istatiksel olarak anlamlı sonuçları göstermektedir. 
$p=0,005), \quad \mathrm{AMH}(2,99 \pm 2,39$ vs. $2,70 \pm 3,19$, $p=0,002)$, elde edilen oosit sayısı $(11,54 \pm 6,87 \mathrm{vs}$. $9,81 \pm 7,61, p=0,003)$, elde edilen MII oosit sayısı $(9,55 \pm 6,2$ vs. $7,57 \pm 5,91, p=0,001)$, embriyo kalitesi $\left(x^{2}=13,46, p<0,001\right)$ ve 5 . gün embriyo transfer oranı $\left(X^{2}=15,40, p<0,0001\right)$ istatiksel olarak anlamlı bulundu. VKI $(p=0,814)$, bazal E2 seviyesi $(p=0,411)$, hCG günü E2 seviyesi $(p=0,056)$, hCG günü $\mathrm{P}$ seviyesi $(p=0,119)$, $\mathrm{ET}$ günü $\mathrm{EMK}(p=0,146)$, maturasyon indeksi $(p=0,140)$ ve TPMSS'da $(p=0,747)$ her iki grup arasında anlamlı bir fark gözlenmedi. Kadın yaşı, VKI, embriyo transfer günü EMK ve elde edilen oosit sayısı kendi içinde gruplandırılarak değerlendirildiğinde gruplar arasında istatiksel olarak anlamlı fark bulunmamıştır. İnfertilite nedenlerinin gebelik oluşumuna etkisi değerlendirildiğinde de gruplar arasında anlamlı fark olmadığı $(p=0,070)$ görüldü.
Tablo 3'te gösterilen parametrelerin çoklu regresyon analizine göre, sadece kadın yaşı [OR:0,946 (0,901-0,995), $p=0,03]$ ve transfer edilen embriyonun kalitesinin gebelik başarısı üzerinde istatistiksel olarak anlamlı bir etkiye sahip olduğu izlendi. Ayrıca 1. kalite embriyo transferi yapılan sikluslarda, 2. kalite embriyo [OR:0,532 $(0,312-0,908), p=0,021]$ ve 3 . kalite embriyo [OR:0,347 (0,178-0,674), $p=0,002$ ] transferi edilen sikluslara kıyasla sırasıyla 2 ve 3 kat daha yüksek gebelik oranları elde edildi. VKI $(p=0,418)$, AMH $(p=0,543)$, bazal FSH $(p=0,429)$, endometriyal kalınlık $(p=0,751)$ ve alınan metafaz II oosit sayısı $(p=0,078)$ 'da dâhil olmak üzere diğer düzeltilmiş kovaryantlar, ICSI döngülerinde göreceli gebelik başarısında anlamlı bir değişikliğe neden olmamıştır. Klinik gebeliğin elde edildiği ve abort veya canlı doğum ile sonuçlanan sikluslar EMK açısından değerlendirildiğinde anlamlı bir fark izlenmemiştir $(p=0,540)$.

Tablo 3. ICSı sonrası gebelik varlığı açısından çoklu lojistik regresyon analizinin sonuçları

\begin{tabular}{lll}
\hline & Düzeltilmiş OR $(\% 95 \mathrm{Cl})$ & $p$ \\
\hline Yaş & $0,946(0,901-0,995)$ & $\mathbf{0 , 0 3 0}$ \\
VKI & $1,021(0,971-1,073)$ & 0,418 \\
AMH & $0,973(0,889-1,084)$ & 0,543 \\
Basal FSH & $0,973(0,909-1,041)$ & 0,429 \\
Endometriyal kalınlık (mm) & $1,015(0,926-1,112)$ & 0,751 \\
Elde edilen MII oosit & $1,040(0,996-1,086)$ & 0,078 \\
Transfer edilen embriyo kalitesi * (İkinci & & \\
kalite embriyo) & $0,532(0,312-0,908)$ & $\mathbf{0 , 0 2 1}$ \\
(Üçüncü kalite embryo) & $0,347(0,178-0,674)$ & $\mathbf{0 , 0 0 2}$ \\
\hline
\end{tabular}

VKI: vücut kitle indeksi, AMH: antimullerian hormon, FSH: folikül stimulan hormon, OR: odds ratio (tahmini rölatif risk) *birinci kalite embriyo (kategorik değişkenlerde) referans alınmıştır.

$p$ değerinin 0,05 'ten küçük olması $(p<0,05)$ istatiksel olarak anlamlıdır. Kalın ve koyu yazılmış değerler istatiksel olarak anlamlı sonuçları göstermektedir.

\section{Tartışma}

$\mathrm{Bu}$ çalışmada ICSI uygulanan infertil kadınlarda çeşitli prognostik faktörlerin klinik gebelik başarısına etkilerini değerlendirdik. Çalışmamızın sonuçlarına göre gebelik başarısını öngörmede en önemli prognostik faktörler maternal yaş, embriyo kalitesi ve transfer günü olarak bulunurken, endometriyal kalınlık ile klinik gebelik oranları arasında istatiksel olarak anlamlı bir ilişki bulunmadı.

Erken foliküler fazdaki antral folikül sayısı (AFS), FSH, LH, E2 ve İnhibin B değerleri over rezervinin göstergeleridir [12]. $\mathrm{AMH}$, over rezervini gösteren diğer bir güvenilir parametredir ve YÜT'de kullanışlı araçlardan biridir. AMH değerinin düşük olması stimülasyona yanıtın kötü olmasını öngörmede, \%40-97 sensitivite, \%78-92 spesifite, \%22-88 pozitif prediktif değere ve \%97-100 negatif prediktif değere sahiptir. Ancak gebeliği öngörmede ne sensitif ne de spesifik olduğu kanıtlanmıştır [13, 14]. Genel olarak kadınlarda, fertilite oranlarındaki düşüş 25-29 yaş arasında \%4-8, 30-34 yaş arasında \%15-19, 35-39 yaş arası \%26-46 ve $40-45$ yaş arasında ise $\% 95$ kadardır [12]. Infertilite tedavilerinde de artan yaş ile birlikte overyan stimülasyona alınan yanıt progresif olarak azalır. Bunun yanında oosit kalitesi de azalır. IVF döngülerinde transfer için seçilen 
morfolojik olarak normal embriyolar için bile ileri yaş kadınlarda anöploidi prevalansı yüksektir. Bunlara bağlı olarak embriyo implantasyon oranları azalır [15-17]. Farr ve ark. [18] embriyo implantasyonu oluşsa ve ultrasonografik fetal kalp atımları izlense dahi artan yaşla birlikte gebelik kayıplarında artışın olduğunu gösterilmiştir. Yine ABD'de yapılan bir çalışmada canlı doğumla sonuçlanan IVF döngülerinin oranı 35 yaşın altındaki kadınlarda \%41,5, 3537 yaş arası kadınlarda \%31,9, 38-40 yaş arası kadınlarda \%22,1, 41-42 yaş arası kadınlarda $\% 12,4,43-44$ yaş arası kadınlarda \%5 ve 44 yaş üstü kadınlarda \%1 olarak tespit edilmiştir [19]. Çalışmamızda gebelik oluşan sikluslarda, oluşmayan sikluslara kıyasla FSH değeri daha düşük, $\mathrm{AMH}$ değerleri anlamlı olarak değeri ise daha yüksek bulundu. Ancak bunun ICSI döngülerinde göreceli gebelik başarısında anlamlı bir değişikliğe neden olmadığını gördük. Ayrıca maternal yaş arttıkça tedavi sikluslarındaki gebelik başarısının anlamlı olarak azaldığını izledik ve maternal yaşın yardımcı üreme tekniklerinde gebelik başarısını öngörmede önemli bir prognostik faktör olduğu sonucuna ulaştık.

3. gün embriyosunun kalitesini embriyonun blastomer sayısı, blastomerlerin simetrisi ve fragmantasyon oranları belirlerken [20, 21], 5. gün embriyosunda ise kaliteyi blastosel büyüklüğü, iç hücre kitlesi ve trofoektoderm yapıları belirler [10]. Racowsky ve ark. [22] 3. gün embriyolarını morfolojik olarak değerlendirmişler ve sonuç olarak hücre sayısının, fragmantasyon ve asimetri oranının viabiliteyi etkilediğini göstermişlerdir. Embriyo kalitesi, implantasyon başarında önemli bir rol oynar. Irani ve ark. [23] öploid blastokistlerin seçiminde morfolojik değerlendirmenin kullanılması gerektiğini ve her embriyo için morfolojik ve iç hücre kitle derecelendirmesinin devam eden klinik gebelik oranları için kullanışlı bir prediktör olduğunu belirtmiştir. Yine Bakkensen ve ark. [24] 2019 yılı çalışmalarında blastosel büyüklüğü ve trofoektoderm kalitesinin klinik gebelik ve canlı doğum ile ilişkili olduğunu göstermiştir. Çalışmamızda da yüksek kalitedeki embriyoların transfer edildiği sikluslarda klinik gebelik oranları anlamlı olarak daha yüksek bulundu. Gebelik oluşan sikluslar kendi içinde değerlendirildiğinde ise 1. kalite embriyo transfer edilen sikluslarda, 2. ve 3. kalite embriyo transfer edilen sikluslara kıyasla sırasıyla 2 ve 3 kat daha yüksek gebelik oranları elde edildiği izlendi.

Çalışmamızda 5. günde embriyo transferi yapılan tedavi sikluslarında, 3. gün transferi yapılanlara kıyasla daha yüksek klinik gebelik oranları bulundu. Doğal yolla oluşan gebeliklerde embriyo uterotubal bileşkeden 3. günün geç, 4. günün de erken safhalarında geçer. Teorik olarak embriyonun daha geç transferi embriyonun doğal döngüdekine daha yakın bir uterus ortamıyla karşılaşmasına neden olabilir. Ayrıca kültür süresi 2-3 gün daha uzatılırsa embriyonun kendi kendine seçimi, 3 . günde embriyonik genomun aktivasyonundan sonra gerçekleşecektir. Böylece embriyolar in vitro blastokist haline gelerek daha yüksek implantasyon potansiyeline sahip olabilirler. Bunu destekler şekilde Milki ve ark. [25] 5. gün embriyosu transferi yapılan sikluslarda, 3. gün embriyosu transferi yapılanlara kıyasla daha yüksek implantasyon ve gebelik oranları bulunmuştur. Bunun 5. günde embriyo seçiminin daha iyi olmasına, gelişmiş embriyo-uterin senkronizasyonuna ve azalmış servikal mukus miktarına bağlı olduğunu belirtmişlerdir. 2016'da yayınlanan Cochrane meta-analizinde de blastokist evresindeki taze embriyo transferinin klivaj safhasındaki embriyo transferine göre daha yüksek canlı doğum (düşük kalitede kanıt) ve klinik gebelik (orta kalitede kanıt) oranlarına sahip olduğunu bildirilmiştir [26]. Ancak 2017 yılında yapılan bir başka sistematik derleme ve meta-analizde ise klivaj safhasındaki embriyo ile blastokist transferinin klinik gebelik oranları açısından birbirlerine üstünlükleri olmadığı gösterilmiştir [27].

Endometriyal reseptivitenin irdelenmesinde ultrasonografik [28-31] ve histeroskopik [32-35] değerlendirmenin yapıldığı klinik yöntemlerin yanı sıra endometriyal sıvı aspiratının [3640] ve endometriyal doku biopsisinin [41-44] değerlendirildiği histolojik, serolojik ve moleküler birçok çalışma mevcuttur. EMK ölçümü, endometriyal reseptivitenin ultrasonografik göstergelerinden en çok araştırılan parametre olmuştur. Bazı araştırma makalelerinde hCG günü ölçülen endometriyal kalınlık ve total gebelik oranları arasında istatistiksel olarak anlamlı bir ilişki tespit edilmiş olsa da [45-47] aksini belirten yayınlar da mevcuttur [48-51]. Örneğin, Holden ve ark.'nın [52], 6331 hastayla yaptıkları çalışmada endometriyal kalınlık artışı 
ile gebelik ve canlı doğum oranları arasında olumlu bir ilişki olduğu izlenirken, Zhao ve ark. [53], 3317 siklus ile yaptıkları retrospektif kohort çalışmasında EMK ile gebelik başarısı arasında anlamlı bir ilişki bulamamıştır. EMK ve gebelik başarısı arasında anlamlı ilişki bulunan bazı çalışmalarda ayrıca endometrium kalınlığı için optimal bir eşik değer belirlenmeye çalışılmıştır. Örneğin Gallos ve ark.'nın [54] 25767 taze embriyo transferini değerlendirerek yaptıkları çalışmada, optimal endometriyal kalınlık eşik değerinin $10 \mathrm{~mm}$ ve üzeri olduğunda canlı doğum sayılarının artarken gebelik kayıplarının ise azaldığını göstermiştir. Ancak bu eşik değer çalışmalar arasında farklılıklar göstermektedir ve bir standardizasyonu yoktur [55-57]. Literatürde yapılmış çalışmalarda genellikle EMK, hCG trigger günü ölçülmüş ve gebelik başarısı arasındaki ilişki değerlendirilmiştir. Ancak bu dönemdeki endometriyum henüz progesteron etkisine maruz kalmamış ve sekretuvar faza girmemiştir. Yani endometriyum embriyo implantasyonuna hazır bir dönemde değildir. Ölçümün endometriyum-embriyo senkronizasyonunun daha yüksek olacağı ET günüyapılmasının EMK ve implantasyon ilişkisini değerlendirmek için daha uygun olacağını düşünmekteyiz. Bu yüzden çalışmamızda EMK, ET günü ölçülmüştür. Yapılan değerlendirme sonucunda ise EMK ile gebelik başarısı arasında anlamlı bir ilişki bulunmamıştır. Ayrıca EMK ile abort veya canlı doğum ile sonuçlanan sikluslar arasında da istatiksel olarak anlamlı bir fark izlenmemiştir.

Çalışmamıza ait bazı kısıtılıklar mevcuttur. Birincisi, bu çalışmanın retrospektif gözlemsel bir çalışma olmasıdır. İkinci kısıtılıı ise çalışmamızda değerlendirilebilen E2 laboratuvar üst değeri $3000 \mathrm{ng} / \mathrm{L}$ olması nedeniyle bu değerin üstündeki seviyeler belirlenememiştir. Buna bağlı olarak gebelik oluşan sikluslarla, oluşmayan sikluslar arasındaki hCG günü E2 seviyesinde istatiksel anlamlı bir farklılık izlenmediği düşünüldü. Çalışmamızın güçlü yönlerinden biri tek merkezde yapılmış olması, uygulanan sikluslar arasında standart değerlendirme ve tedavi yaklaşımının kullanılmasıdır. Diğer güçlü yönleri ise geniş bir zaman dilimi içerisinde, keskin hasta dişlama kriterleriyle ve nispeten fazla siklus sayısıyla yapılmış olmasıdır.
Sonuç olarak, çalışmamızdan elde ettiğimiz veriler ışığında ICSI yöntemi uygulanan infertil hastalarda gebelik başarısını öngörmede en önemli prognostik faktörlermaternalyaş, embriyo kalitesi ve transfer günüdür. Ancak embriyo implantasyon basamağı hala çözülememiş bir gizemdir. Bu gizemi aydınlatmak ve başarılı gebelik oranları elde etmek için daha geniş ölçekli ve prospektif çalışmalara intiyaç vardır.

Çıkar ilişkisi: Yazarlar çıkar ilişkisi olmadığını beyan eder.

\section{Kaynaklar}

1. Steptoe PC, Edwards RG. Birth after the reimplantation of a human embryo. Lancet 1978;312:366. https://doi. org/10.1016/s0140-6736(78)92957-4

2. Niederberger C, Pellicer A, Cohen J, et al. Forty years of IVF. Fertil Steril 2018;110:185-324.e5. https://doi. org/10.1016/j.fertnstert.2018.06.005

3. Sunderam S, Kissin DM, Zhang Y, et al. Assisted reproductive technology surveillance-United States, 2016. MMWR Surveill Summ 2019;68:1-23 https://doi. org/10.15585/mmwr.ss6804a1

4. Pinter B, da Silav MO, Bloemenkamp K, Fronteira I, Karro H. Assisted reproductive technologies in european union: findings of the reproductive health report, 2018. Available at: https://webgate.ec.europa. eu/chafea_pdb/assets/files/pdb/2007110/2007110_ d12-01_en_ps.pdf. Accepted Feb 24, 2021

5. Pasqualini RS, Quintans CJ. Clinical practice of embryo transfer. Reprod Biomed Online 2002;4:83-92. https:// doi.org/10.1016/s1472-6483(10)61920-7

6. Lessey BA, Young SL. What exactly is endometrial receptivity? Fertil Steril 2019;111:611-617. https://doi. org/10.1016/j.fertnstert.2019.02.009

7. Ferraretti AP, La Marca A, Fauser BC, et al. ESHRE consensus on the definition of 'poor response' to ovarian stimulation for in vitro fertilization: the Bologna criteria. Hum Reprod 2011;26:1616-1624. https://doi. org/10.1093/humrep/der092

8. Cooper TG, Noonan E, von Eckardstein S, et al. World Health Organization reference values for human semen characteristics. Hum Reprod Update 2010;16:231-245. https://doi.org/10.1093/humupd/dmp048

9. Practice Committee of the American Society for Reproductive Medicine. Evidence-based treatments for couples with unexplained infertility: a guideline. Fertil Steril 2020;113:305-322. https://doi.org/10.1016/j. fertnstert.2019.10.014

10. Gardner DK, Schoolcraft WB. Culture and transfer of human blastocysts. Curr Opin Obstet Gynecol 1999;11:307-311. https://doi.org/10.1097/00001703199906000-00013 
11. Practice Committee of the American Society for Reproductive Medicine. Performing the embryo transfer: a guideline. Fertil Steril 2017;107:882-896. https://doi.org/10.1016/j.fertnstert.2017.01.025

12. Erden M. Kadınlarda infertilite. In: Günalp GS, ed. Speroff klinik jinekolojik endokrinoloji ve infertilite, 9.baskı. Ankara: Güneş Tıp Kitabevleri 2020;973-1027.

13. Muttukrishna $\mathrm{S}$, McGarrigle $\mathrm{H}$, Wakim $\mathrm{R}$, Khadum I, Ranieri DM, Serhal P. Antral follicle count, antimullerian hormone and inhibin B: predictors of ovarian response in assisted reproductive technology? BJOG 2005;112:1384-1390. https://doi.org/10.1111/j.14710528.2005.00670.x

14. Gnoth C, Schuring AN, Friol K, Tigges J, Mallmann P, Godehardt E. Relevance of anti-mullerian hormone measurement in a routine IVF program. Hum Reprod 2008;23:1359-1365. https://doi.org/10.1093/humrep/ den108

15. van Rooij IA, Bancsi LF, Broekmans FJ, Looman CW, Habbema JD, te Velde ER. Women older than 40 years of age and those with elevated follicle-stimulating hormone levels differ in poor response rate and embryo quality in in vitro fertilization. Fertil Steril 2003;79:482488. https://doi.org/10.1016/s0015-0282(02)04839-2

16. Ziebe S, Loft A, Petersen JH, et al. Embryo quality and developmental potential is compromised by age. Acta Obstet Gynecol Scand 2001;80:169-174. https://doi. org/10.1034/j.1600-0412.2001.080002169.x

17. Hull MG, Fleming CF, Hughes AO, McDermott A. The age-related decline in female fecundity: a quantitative controlled study of implanting capacity and survival of individual embryos after in vitro fertilization. Fertil Steril 1996;65:783-790. https://doi.org/10.1016/s00150282(16)58214-4

18. Farr SL, Schieve LA, Jamieson DJ. Pregnancy loss among pregnancies conceived through assisted reproductive technology, United States, 1999-2002. Am J Epidemiol. 2007;165:1380-1388. https://doi. org/10.1093/aje/kwm035

19. Centers for disease control and prevention, American society for reproductive medicine society for assisted reproductive technology. 2010 assisted reproductive technology: fertility clinic success rates report. Atlanta (GA): CDC; 2012. Available at: http://www.cdc.gov/ art/ART2010/PDFs/ART_2010_Clinic_Report-full.pdf. Accessed Feb 28, 2012

20. Scott L. Analysis of fertilization. Textbook of assisted reproductive techniques. Gardner DK, Weissman A, Howles CM, Shoham Z, ed. London, United Kingdom: Martin Dunitz Ltd 2001;281-296.

21. Gardner DK, Sakkas D. Assessment of embryo viability: the ability to select a single embryo for transfer-a review. Placenta 2003;24:5-12. https://doi.org/10.1016/ s0143-4004(03)00136-x
22. Racowsky C, Combelles CM, Nureddin A, et al. Day 3 and day 5 morphological predictors of embryo viability. Reprod Biomed Online 2003;6:323-331. https://doi. org/10.1016/s1472-6483(10)61852-4

23. Irani $\mathrm{M}$, Reichman $\mathrm{D}$, Robles $\mathrm{A}$, et al. Morphologic grading of euploid blastocysts influences implantation and ongoing pregnancy rates. Fertil Steril 2017;107:664670. https://doi.org/10.1016/j.fertnstert.2016.11.012

24. Bakkensen JB, Brady P, Carusi D, Romanski P, Thomas AM, Racowsky C. Association between blastocyst morphology and pregnancy and perinatal outcomes following fresh and cryopreserved embryo transfer. J Assist Reprod Genet 2019;36:2315-2324. https://doi. org/10.1007/s10815-019-01580-0

25. Milki AA, Hinckley MD, Fisch JD, Dasig D, Behr B. Comparison of blastocyst transfer with day 3 embryo transfer in similar patient populations. Fertil Steril 2000;73:126-129. https://doi.org/10.1016/s00150282(99)00485-9

26. Glujovsky D, Farquhar C, Quinteiro Retamar AM, Alvarez Sedo CR, Blake D. Cleavage stage versus blastocyst stage embryo transfer in assisted reproductive technology. Cochrane Database Syst Rev 2016;6:CD002118. https://doi.org/10.1002/14651858. CD002118.pub5

27. Martins WP, Nastri CO, Rienzi L, van der Poel SZ, Gracia C, Racowsky C. Blastocyst vs cleavage-stage embryo transfer: systematic review and meta-analysis of reproductive outcomes. Ultrasound Obstet Gynecol 2017;49:583-591. https://doi.org/10.1002/uog.17327

28. Ahmadi F, Akhbari F, Zamani M, Ramezanali F, Cheraghi R. Value of endometrial echopattern at HCG administration day in predicting IVF outcome. Arch Iran Med 2017;20:101-104.

29. Ghamdi A, Coskun S, Al Hassan S, Al Rejjal R, Awartani $\mathrm{K}$. The correlation between endometrial thickness and outcome of in vitro fertilization and embryo transfer (IVF-ET) outcome. Reprod Biol Endocrinol 2008;6:37. https://doi.org/10.1186/1477-7827-6-37

30. Aydin T, Kara M, Nurettin T. Relationship between endometrial thickness and in vitro fertilizationintracytoplasmic sperm injection outcome. Int J Fertil Steril 2013;7:29-34.

31. Dechaud H, Bessueille E, Bousquet PJ, Reyftmann L, Hamamah S, Hedon B. Optimal timing of ultrasonographic and doppler evaluation of uterine receptivity to implantation. Reprod Biomed Online 2008;16:368-375. https://doi.org/10.1016/s14726483(10)60598-6

32. Inafuku K. Hysteroscopy in midluteal phase of human endometrium evaluation of functional aspect of the endometrium. Nihon Sanka Fujinka Gakkai Zasshi 1992;44:79-83. 
33. Li S, Pan P, Yao S, et al. Hysteroscopic appearence of midsecretory endometrium in relation to pinopodes expression and the reproductive outcome in infertile women. J Reprod Contracept 2010;21:17-26.

34. Santi A, Felser R, Bersinger NA, Wunder DM, McKinnon $B$, Mueller DM. The hysteroscopic view of infertility: the mid-secretory endometrium and treatment success towards pregnancy. Gynecol Surg 2012;9:147-150. https://doi.org/10.1007/s10397-011-0687-3

35. Masamoto H, Nakama K, Kanazawa K. Hysteroscopic appearance of the mid-secretory endometrium: relationship to early phase pregnancy outcome after implantation. Hum Reprod 2000;15:2112-2118. https:// doi.org/10.1093/humrep/15.10.2112

36. Halperin R, Ron El R, Golan A, et al. Implantation: uterine fluid human decidua-associated protein 200 and implantation after embryo transfer. Hum Reprod 1995;10:907-910. https://doi.org/10.1093/ oxfordjournals.humrep.a136059

37. Florio P, Bruni L, De Falco $\mathrm{C}$, et al. Evaluation of endometrial urocortin secretion for prediction of pregnancy after intrauterine insemination. Clin Chem 2008;54:350-355. https://doi.org/10.1373/ clinchem.2007.094987

38. Florio P, Bruni L, Galleri L, et al. Evaluation of endometrial activin A secretion for prediction of pregnancy after intrauterine insemination. Fertil Steril 2010;93:2316-2320. https://doi.org/10.1016/j. fertnstert.2008.12.125

39. Rahiminejad ME, Moaddab A, Ebrahimi M, et al. The relationship between some endometrial secretion cytokines and in vitro fertilization. Iran J Reprod Med 2015;13:557-562. Available at: https://www.ncbi.nlm. nih.gov/pmc/articles/PMC4637123/pdf/ijrm-13-557. pdf. Accepted June 21, 2015

40. Rahiminejad ME, Moaddab A, Ganji M, et al. Oxidative stress biomarkers in endometrial secretions: a comparison between successful and unsuccessful in vitro fertilization cycles. J Reprod Immunol 2016;116:7075. https://doi.org/10.1016/j.jri.2016.05.003

41. Jin XY, Zhao LJ, Luo DH, et al. Pinopode score around the time of implantation is predictive of successful implantation following frozen embryo transfer in hormone replacement cycles. Hum Reprod 2017;32:2394-2403. https://doi.org/10.1093/humrep/ dex312

42. Mahajan N. Endometrial receptivity array: clinical application. J Hum Reprod Sci 2015;8:121-129. https:// doi.org/10.4103/0974-1208.165153

43. Michimata T, Ogasawara MS, Tsuda $\mathrm{H}$, et al. Distributions of endometrial NK cells, B cells, T cells, and Th2/Tc2 cells fail to predict pregnancy outcome following recurrent abortion. Am J Reprod Immunol 2002;47:196-202. https://doi.org/10.1034/j.16000897.2002.01048.x
44. Ruiz Alonso M, Blesa D, Díaz Gimeno P, et al. The endometrial receptivity array for diagnosis and personalized embryo transfer as a treatment for patients with repeated implantation failure. Fertil Steril 2013;100:818-824. https://doi.org/10.1016/j. fertnstert.2013.05.004

45. Al Ghamdi A, Coskun S, Al Hassan S, Al Rejjal R, Awartani K. The correlation between endometrial thickness and outcome of in vitro fertilization and embryo transfer (IVF-ET) outcome. Reprod Biol Endocrinol 2008;6:37. https://doi.org/10.1186/14777827-6-37

46. Chen SL, Wu FR, Luo C, et al. Combined analysis of endometrial thickness and pattern in predicting outcome of in vitro fertilization and embryo transfer: a retrospective cohort study. Reprod Biol Endocrinol 2010;8:30. https://doi.org/10.1186/1477-7827-8-30

47. Richter KS, Bugge KR, Bromer JG, Levy MJ. Relationship between endometrial thickness and embryo implantation, based on 1,294 cycles of in vitro fertilization with transfer of two blastocyst-stage embryos. Fertil Steril 2007;87:53-59. https://doi. org/10.1016/j.fertnstert.2006.05.064

48. Laasch C, Puscheck E. Cumulative embryo score, not endometrial thickness, is best for pregnancy prediction in IVF. J Assist Reprod Genet 2004;21:47-50. https:// doi.org/10.1023/b:jarg.0000025937.43936.73

49. Yoeli R, Ashkenazi J, Orvieto R, Shelef M, Kaplan B, Bar Hava I. Significance of increased endometrial thickness in assisted reproduction technology treatments. J Assist Reprod Genet 2004;21:285-289. https://doi.org/10.1023/b:jarg.0000043701.22835.56

50. Rashidi BH, Sadeghi M, Jafarabadi M, Tehrani Nejad ES. Relationships between pregnancy rates following in vitro fertilization or intracytoplasmic sperm injection and endometrial thickness and pattern. Eur J Obstet Gynecol Reprod Biol 2005;120:179-184. https://doi. org/10.1016/j.ejogrb.2004.08.016

51. Corbacioğlu A, Baysal B. Effects of endometrial thickness and echogenic pattern on assisted reproductive treatment outcome. Clin Exp Obstet Gynecol 2009;36:145-147.

52. Holden EC, Dodge LE, Sneeringer R, Moragianni VA, Penzias AS, Hacker MR. Thicker endometrial linings are associated with better IVF outcomes: a cohort of 6331 women. Hum Fertil (Camb) 2018;21:288-293. https://doi.org/10.1080/14647273.2017.1334130

53. Zhao J, Zhang Q, Wang Y, Li Y. Endometrial pattern, thickness and growth in predicting pregnancy outcome following 3319 IVF cycle. Reprod Biomed Online. 2014;29:291-298. https://doi.org/10.1016/j. rbmo.2014.05.011 
54. Gallos ID, Khairy M, Chu J, et al. Optimal endometrial thickness to maximize live births and minimize pregnancy losses: analysis of 25,767 fresh embryo transfers. Reprod Biomed Online 2018;37:542-548. https://doi.org/10.1016/j.rbmo.2018.08.025

55. Chan JM, Sukumar AI, Ramalingam M, Ranbir Singh SS, Abdullah MF. The impact of endometrial thickness (EMT) on the day of human chorionic gonadotropin (hCG) administration on pregnancy outcomes: a 5-year retrospective cohort analysis in Malaysia. Fertil Res Pract 2018;4:5. https://doi.org/10.1186/s40738-0180050-8

56. Tomic V, Kasum M, Vucic K. Impact of embryo quality and endometrial thickness on implantation in natural cycle IVF. Arch Gynecol Obstet 2020;301:1325-1330. https://doi.org/10.1007/s00404-020-05507-4

57. Kasius A, Smit JG, Torrance HL, et al. Endometrial thickness and pregnancy rates after IVF: a systematic review and meta-analysis. Hum Reprod Update 2014;20:530-541. https://doi.org/10.1093/humupd/ dmu011

Etik kurul onayı: Pamukkale Üniversitesi Girişimsel Olmayan Klinik Araştırmalar Etik Kurulu'nun 18.02.2021 tarih ve 20632 sayılı kararı ile etik onayı alındı.

Teşekkür: Pamukkale Üniversitesi Tıp Fakültesi Kadın Hastalıkları ve Doğum A.D., Histoloji ve Embriyoloji A.D. ve Yardımcı Üreme Teknikleri Merkezi'nde çalışan başta Prof. Dr. Babür Kaleli, Prof. Dr. S. Erkan Alataş, Prof. Dr. İ. Veysel Fenkçi ve Prof. Dr. Gülçin Mete hocalarımız olmak üzere tüm çalışma arkadaşlarımıza teşekkür ederiz.

\section{Yazarların makaleye olan katkıları}

Ü.Ç. ve C.K. çalışmanın ana fikrini ve hipotezini kurgulamışlardır. Ü.Ç., C.K. ve N.Ç. teoriyi geliştirmiş, gereç ve yöntem bölümünü düzenlemişlerdir. Sonuçlar kısmındaki verilerin değerlendirmesini Ü.Ç. ve C.K. yapmıştır. Makalenin tartışma bölümü Ü.Ç tarafından yazıımıştır. Ü.Ç., C.K. ve N.Ç. makaleyi gözden geçirip gerekli düzeltmeleri yapmış ve onaylamıştır. Her üç yazar da çalışmanın tamamını tartışmış ve son halini onaylamıştır. 